\title{
ANÁLISIS COMARCAL DE LAS ACTIVIDADES EMPRESARIALES DE I+D EN ANDALUCÍA
}

\author{
Francisca Ruiz Rodríguez \\ Departamento de Geografía Física y Análisis Geográfico Regional \\ Universidad de Sevilla
}

\section{RESUMEN}

En este trabajo se analiza los factores territoriales y sectoriales que impulsan las actividades de $\mathrm{I}+\mathrm{D}$ en el sector empresas en una región periférica como Andalucía. En este tipo de regiones la dimensión y las características de la dispersión espacial de estas actividades están en relación con la disposición territorial y con un mínimo grado de diversificación productiva y tecnológica del tejido empresarial. A través de la aplicación de la técnica shift-share se puede apreciar como para el caso andaluz en la mayor parte de su territorio no se dan condiciones ni sectoriales ni territoriales para la generación de I+D en el sector privado y cuando éstas se dan están íntimamente relacionadas. Las comarcas más dinámicas son las áreas metropolitanas de Sevilla y Málaga, las aglomeraciones urbanas de la Bahía de Cádiz, Granada, Córdoba, Huelva y Almería junto con el Poniente Almeriense; ámbitos con una estructura productiva de innovación muy diversificada y en la que está presente las medias-altas y altas tecnologías.

Palabras clave: Investigación y Desarrollo Tecnológico (I+D), Sector empresas, Difusión Territorial, Regiones periféricas, Factor Territorial y Sectorial, Andalucía.

\section{SUMMARY}

This work analyses the territorial and sectorial factors which drive $\mathrm{R}+\mathrm{D}$ in the business sector in a peripheral region such as Andalucía. In these kinds of regions the size and characteristics of the spatial dispersion of these activities is related to territorial layout and to a minimum level of productive and technological diversification of the business fabric. Through the application of the shift-share technique one can appreciate how in the case of Andalucía throughout most of its territory neither the sectorial or territorial conditions are present to generate $\mathrm{R}+\mathrm{D}$ in the private sector, and when they do exist they are intimately connected. The most dynamic administrative areas are the metropolitan areas of Sevilla and Málaga, the urban agglomerations of the Bay of Cádiz, 
Granada, Córdoba, Huelva and Almería together with the area to the west of Almería; environments with a productive structure of very diversified innovation in which medium-high and high technologies are present.

Key words: Technological Research and Development (R+D), Business Sector, Territorial Distribution, Peripheral Regions, Territorial and Sectorial Factor, Andalucía.

\section{Introducción}

En nuestros días los contrastes espaciales a cualquier escala de estudio (regional, intrarregional) tienen más bien caracteres cualitativos que cuantitativos (Méndez, 1997 b) ya que son el resultado de las diferentes capacidades que gozan los territorios para producir o incorporar innovaciones. La situación relativa que ocupan las regiones en función de su nivel de desarrollo en el marco europeo o a cualquier otra escala está asociada claramente a la capacidad innovadora de su tejido productivo. Y especialmente a la tenencia de un fuerte subsistema empresarial de innovación que traduzca los nuevos conocimientos (tecnología) producidos o adquiridos por el sistema de innovación regional en productos en el mercado.

Los procesos de propagación de la innovación generalmente han sido estudiados desde un punto de vista sectorial a partir de las aportaciones de toda la literatura del cambio tecnológico en donde se resalta la importancia que tiene la variable sectorial o el área tecnológica en el modo de innovar. Independientemente del país (región, territorio) en que estuvieran ubicados los centros u organismos que innoven, existen unos sectores que se caracterizan por una alta intensidad de I+D, otros por una intensidad media y otros por intensidad baja. Es la pertenencia a un sector o área tecnológica la que fija, en este caso, el límite o frontera espacial del sistema de innovación, y no un límite geográfico determinado (los sistemas tecnológicos de Carlsson (1995) y los sistemas sectoriales de innovación de Bresci y Malerba (1997)).

Pero por otra parte los defensores de los sistemas nacionales o regionales de innovación adjudican una gran importancia a la proximidad espacial, las externalidades, la cultura e identidad regional y el proceso de aprendizaje colectivo o regional en la creación y difusión de las innovaciones (Koschatzky, 2000). Se entiende por Sistemas de Innovación Nacional y/o Regional los sistemas compuestos por las organizaciones e instituciones de un país que influyen en el desarrollo, difusión y uso de las innovaciones (Edquist, 1997, pág. 14). Una definición teórica del concepto de SNRI ${ }^{1}$ tiene en cuenta tres aspectos. Primero se trata de un «sistema» donde actúan e interactúan distintos agentes e instituciones; segundo, las actividades analizadas están ligadas a la «innovación»; y tercero, se trata de un sistema nacional o regional, lo que implica un «enfoque geográfico» (Heijs, 2001).

1 Es un concepto que parte de la fusión de dos enfoques teóricos. Por un lado se basa en los noción de distrito industrial (Marshall, 1919), polos de crecimiento (Perroux, 1955) y en la teoría de los clusters (Porter, 1990) y por otro se fundamenta en los resultados de la teoría del crecimiento que subrayan la importancia de la innovación en el progreso y desarrollo económico para las áreas geográficas. Las actividades innovadoras generan externalidades positivas (Romer, 1986, 1990; Lucas, 1988) que pueden ser aprovechadas, sobre todo, por los agentes regionales (Stern, Porter, Furman, 2000). 
De esta forma innovar a través de actividades de $\mathrm{I}+\mathrm{D}^{2}$ o de otras actividades innovadoras $^{3}$, se considera un proceso complejo e iterativo en el que el conocimiento tácito, las competencias específicas, los activos complementarios (Teece, 1987) y los sistemas nacionales de innovación desarrollados (Lundvall, 1992) juegan papeles decisivos. La innovación necesita por tanto de la adquisición y síntesis de muchos tipos de conocimientos, y el propio conocimiento debe ser transformado una vez adquirido de fuentes externas. Esas fuentes pueden estar en el mismo territorio o fuera de éste. Es decir, las relaciones que se establecen para la creación de conocimiento se convierten a su vez en mecanismos de difusión de las innovaciones. El conocimiento fluye a través de redes, cada vez más complejas, que conllevan dinámicas tanto de colaboración como de competencia.

La teoría porteriana parte de la idea de que si las empresas innovan para ser competitivas en sus mercados o para ampliar éstos últimos, un Territorio es más competitivo cuanto mayormente posea una red de empresas relacionadas de forma vertical (cliente-proveedor) y horizontal (intra e intersectorial) en productos especializados o innovadores (Porter, 1990). Por lo tanto esta teoría reafirma las consideraciones del desarrollo del territorio desde el punto de vista local (Teoría del desarrollo endógeno). Para esta última, como señala Aydalot (1986 a y b), el desarrollo económico de un territorio no se apoya sólo en la capacidad de adquirir tecnología sino que depende, también, de la capacidad innovadora del sistema productivo de cada localidad. La magnitud de la innovación en un territorio viene dada por la confluencia de los intercambios de productos y recursos entre las empresas, la multiplicidad de las relaciones entre los actores, y la transmisión de mensajes e informaciones que existan entre ellos. Estas relaciones propician la difusión de innovaciones, impulsan el aumento de la productividad y mejoran la competitividad de las empresas locales (Vázquez Barquero, 1997). A semejanza de la teoría de Porter, los defensores del desarrollo endógeno destacan la importancia de la administración pública en el desarrollo innovador y global de algunas localidades y regiones.

2 Las actividades de Investigación y Desarrollo Tecnológico quedan definidas como «el conjunto de trabajos creativos que se emprenden de modo sistemático a fin de aumentar el volumen de conocimientos, incluidos el conocimiento del hombre, la cultura y la sociedad, así como la utilización de esa suma de conocimientos para concebir nuevas aplicaciones» (OCDE, 1994).

Las actividades de I+D engloban la investigación básica, la investigación aplicada y las actividades de desarrollo tecnológico. Aunque, en algunos casos es difícil distinguir la I+D de otras actividades científicotecnológicas será la existencia, en el seno de la I+D, de «un elemento apreciable de creatividad y la resolución de una incertidumbre científica y/o tecnológica; o dicho de otra manera, cuando la solución de un problema no parezca evidente a cualquiera que esté al corriente del conjunto de conocimientos y técnicas básicas utilizadas comúnmente en el sector considerado».

3 Otras actividades innovadoras. Aparte de las actividades de I+D internas o externas (compra de servicios) las actividades innovadoras de carácter tecnológico (nuevos productos introducidas en el mercado y procesos, así como las modificaciones tecnológicas importantes de los mismos) en el mercado (innovación de producto) o utilizada en un proceso de producción (innovación de proceso) según el Manual de Oslo se pueden resumir en adquisición de tecnología inmaterial (patentes e invenciones no patentadas, licencias, informes de know-how, marcas de fábrica, diseños, modelos de utilidad, compra de servicios de I+D y otros servicios con un contenido tecnológico; adquisición de maquinaria y equipo; Actividades de diseño e ingeniería industrial, utillaje y lanzamiento de la fabricación; Conjunto de actividades asociadas al lanzamiento de un nuevo producto y Actividades de formación relacionados con la introducción de nuevos productos y procesos.

Por innovaciones no tecnológicas se entiende todos aquellos cambios introducidos por la empresa con el fin de mejorar su funcionamiento y competitividad. Se consideran los siguientes tipos de novedades: Innovación organizativa; Innovación estratégica; Innovación comercial; Innovación operativa e Innovación "tecnológica» entendiendo por esta última la adquisición de nuevo equipo no relacionado con nuevos productos o procesos (automatización de procesos rutinarios, eficiencia en los procesos avanzados de información y comunicación, etc.). 
Desde la Geografía, Salom et al. (1999) siguiendo el modelo teórico propuesto por Dematteis (1995) señala que la dinámica del territorio a través de formas de organización de la producción y del conocimiento viene condicionada por cuestiones sectoriales ya que las relaciones de dependencia o simétricas de un territorio (región o de los nodos regionales) no están ya en relación con los nodos (como en las redes christallerianas) sino más bien con el tipo de actividades presentes (sectores innovadores o maduros, en expansión o en regresión), con la estructura de las empresas que en ellos operan (pequeñas o grandes y sus enlaces), con la gama de especializaciones presentes y a la historia particular de cada nodo.

Desde la disciplina geográfica y en regiones periféricas interesa conocer y verificar como el espacio relacional de carácter productivo y cognoscitivo organiza, dinamiza al territorio regional y se convierte en palanca de la economía, desarrollando factores específicos de carácter endógeno (Jordá, 2004). A este tipo de regiones le interesa que la creación de I+D e innovación se difunda por todo el territorio y no se externalice en parte fuera de ésta al no encontrar la suficiente demanda en el ámbito territorial. Ya que hay que tener presente que la creación y absorción de conocimientos en las empresas no depende sólo de los esfuerzos individuales de cada uno de ellas sino también de toda aquella información a la que se tiene acceso. Es decir en el proceso de producción de la innovación compete a la empresa y al resto de conjunto de empresas e instituciones que intervienen en la cooperación o compra-venta en un determinado territorio.

De esta forma la configuración del sistema de relaciones con el entorno local y externo incide positivamente o negativamente en la competitividad, la innovación y la diferenciación del tejido productivo de ese territorio. Entre los factores que definen un sistema de relaciones se pueden citar: el número de empresas innovadoras competitivas a escala internacional de cada sector, el grado de innovación de los productos desarrollados, la importancia de las relaciones intersectoriales e intrasectoriales de mercado del tejido innovador regional, las relaciones con el resto de agentes del sistema de innovación regional y por último la localización de las empresas innovadoras y de I+D.

Resumiendo se puede diferenciar dos grandes factores que impulsan las actividades de I+D y la innovación en un territorio, y que se pueden mostrar de forma individualizada o conjunta:

a) Una especialización en ramas productivas de alto grado tecnológico que fomentan el desarrollo de actividades de I+D o innovadoras a través de fuertes relaciones con proveedores-clientes vertical (local) y de carácter horizontal (intersectoriales).

b) La existencia de ciertas condiciones territoriales como la actuación de economías externas y apoyos institucionales. La propia aglomeración espacial de empresas innovadoras y de otros agentes innovadores genera un cierto volumen de economías externas a cada uno de ellos en particular, pero internas al conjunto territorial de referencia gracias a la oportunidad que ofrece la proximidad espacial de todos los agentes para la formación de redes formales o informales.

En este trabajo se presentan los resultados del análisis de la difusión territorial de las actividades de I+D privadas en una región periférica como Andalucía a escala comarcal. Para ello se estudia por una parte la localización de las empresas de I+D e innovadoras y por otra la especialización sectorial de las comarcas andaluzas. Con dicha información se valora el factor territorial y sectorial en la proliferación de actividades de I+D por el territorio a partir de la técnica shift-share (reparto proporcional). 


\section{Una excesiva concentración espacial de las actividades de I+D empresariales}

Las regiones periféricas como Andalucía ${ }^{4}$ se caracterizan por una excesiva concentración espacial del tejido empresarial que realiza actividades de I+D. Aunque su localización está en clara asociación con la ubicación territorial de empresas que realizan otras actividades innovadoras (con un coeficiente de correlación de Pearson del 0,96 a un nivel de significación del 0,01 ), aquellas tienen un carácter más centralizado desde el punto de vista territorial. Innovar a través de actividades de I+D o de otras actividades innovadoras, es un fenómeno altamente selectivo desde el punto de vista espacial, y más en regiones con bajos niveles de desarrollo. Las empresas innovadoras andaluzas tienden a localizarse en las comarcas $^{5}$ que dibujan las capitales provinciales, a las que se le tendría que sumar la comarca de Linares, el Poniente Almeriense y el Subbético Cordobés (mapa 1).

Los ámbitos territoriales con mayor representación de actividades de I+D empresariales prácticamente coinciden con las comarcas o áreas metropolitanas más innovadoras mostrándose mayor grado de concentración espacial y una menor continuidad espacial en la localización de las actividades de I+D que en el resto de actividades innovadoras. Las empresas de I+D se concentran en el área metropolitana de Sevilla (36,36\%), Málaga (10,77\%), Poniente Almeriense (5,72\%), Granada (5,39\%), Córdoba (4,38\%), Bahía de Cádiz (3,70\%), Almería (2,36\%) y Sierra Sur-Martos (2,39\%). Mientras que por el contrario su presencia es anecdótica o inexistente en las comarcas serranas de Sierra Morena, Cádiz y en las más orientales de Granada (mapa 2).

Las pautas de localización de la innovación y la I+D están asociadas claramente al espacio urbano y a los grandes corredores viarios. Los ejes innovadores que se perfilan en la región se articulan a través de principales arterias de comunicación de la Comunidad Autónoma y por sus capitales provinciales. En primer lugar un eje interior en torno a la carretera Nacional IV o autovía de Andalucía con centralidad en Sevilla que se prolonga hacia a) las comarcas costeras de Huelva (autovía Quinto Centenario), b) Cádiz por la autovía de Andalucía y la autopista Sevilla-Cádiz, c) Córdoba por la autovía de Andalucía, d) Málaga por la A-92 y c) hacia Andalucía oriental por la autovía A-92. Es en concreto en la comarca de Antequera, cruce de caminos, en donde este eje se entrelaza con otro interior, más incipiente, que se extiende desde la Comarca Sierra Sur de Sevilla hasta Linares y Úbeda siguiendo los ejes transversales: Córdoba-Málaga y Bailén-Motril. Y en último lugar otro más discontinuo, costero en torno a la autovía del Mediterráneo y con centro en Málaga.

Sin embargo el esfuerzo comarcal en $\mathrm{I}+\mathrm{D}^{6}$ de las áreas más innovadoras (capitales provinciales, y otras) es más bajo que las comarcas que concentran menor número de empresas de $\mathrm{I}+\mathrm{D}$. Las comarcas que tienen mayor proporción de empresas de I+D con relación al conjunto innovador son aquellas que están más cercanas a las áreas urbanas y serranas limítrofes al Valle del Guadalquivir junto con el Levante y Poniente almeriense (Corredor de la Plata, Medio Guadalquivir, Condado de Jaén, Sierra Sur-Martos, Almanzora, Condado-Doñana y en menor medida los Pedroches y Poniente Granadino).

4 Región Objetivo 1. Según datos aportados por la Comisión Europea (2004) la renta per cápita (SPA) de Andalucía en el año 2001 es del 63,1 de la media de la Unión Europea de los 15 y del 69,2 con respecto a la media de la U.E. ampliada a 25 países. Además posee una tasa de paro muy elevada (22,3\%) en el $2002(19,6 \%)$.

5 La base comarcal utilizada es la elaborada por el grupo de Investigación Estudios Geográficos Andaluces publicada en el 2002 (Dir. G. Cano García). Véase Anexo I.

6 Esfuerzo comarcal en I+D: proporción de empresas de $\mathrm{I}+\mathrm{D}$ con respecto al total de empresas innovadoras. 


\section{Innovación y especialización sectorial del territorio andaluz}

La disposición espacial de la innovación tiene claramente una componente sectorial. Las pautas de localización de las empresas industriales de base científica (Pavitt, 1984) ${ }^{7}$ extensible en cierta forma a las de servicios, y en cualquier escala espacial de estudio, se contrapone a la de las industrias intensivas en producción a gran escala. Las primeras más necesitadas de las externalidades que ofrecen los espacios centrales tienen un elevado grado de concentración territorial. Mientras que la descentralización y la deslocalización es característica de los sectores maduros, intensivos en el uso de la mano de obra poco cualificada y recursos naturales, en donde la principal competencia se produce en términos de coste. Pero hay que tener en cuenta como advierte Méndez, 1997 a y b que en regiones periféricas las industrias calificadas como de alta o nueva tecnología ${ }^{8}$ identificables con los sectores motores son las que han llevado a cabo una mayor segmentación interna de sus tareas, disgregadas espacialmente en el seno de grandes empresas multinacionales de ámbito transnacional pueden llevarnos a conclusiones erróneas en tanto se trata de la descentralización de ciertas actividades (muy especializadas, de escaso valor añadido, de uso eventual...) hacia PYMEs que ocupan posiciones marginales dentro del sector (Ruiz, 2003).

El territorio andaluz se caracteriza desde el punto de vista de la innovación no sólo por la macrocefalia urbana sino también por la monoespecialización y poca intensidad tecnológica sectorial. La mayor parte de las comarcas andaluzas cuentan con una escasa diversidad sectorial y un bajo grado tecnológico de las firmas de I+D. El predominio de una estructura innovadora dominada por proveedores y de producción a gran escala implica no sólo la ausencia de necesidad de realizar grandes inversiones en I+D sino que además el potencial de difusión de innovación de alto valor añadido es muy reducido.

Por otra parte en este tipo de regiones no todas las empresas innovadoras pertenecientes a ramas de base científica y de proveedores especializados basan su innovación en actividades de I+D. La mayor parte de ellas son PYMES subcontratadas o filiales de multinacio-

7 Pavitt en 1984 clasifica los patrones de innovación de los sectores de la economía en cuatro categorías: Sectores dominados por los proveedores $(D P)$, Sectores productores a gran escala (PGE), Sectores proveedores especializados (PE) y Sectores de base científica $(B C)$. En 1989 Pavitt et al. añaden una nueva categoría a la clasificación sectorial: los sectores «intensivos en información. Al mismo tiempo, Soete y Miozzo (1989) consideran distintos estilos innovadores de las actividades de servicios. Identifican cuatro tipos de empresas o sectores en los servicios: Sectores dominados por los proveedores Servicios intensivos en producción, intensivos en escala y servicios de redes, Proveedores Especializados en tecnología y sectores de Base científica.

De todas maneras hay que tener presente que las dos clasificaciones poseen ciertas limitaciones. Entre ellas podemos destacar: a) ambas resaltan mucho la innovación tecnológica, olvidándose de la no tecnológica, tan frecuente en el sector servicios; b) la existencia de sectores, como el de las comunicaciones o empresas de servicios avanzados que pueden situarse en más de una categoría, c) la asignación de los sectores CNAE a los grupos de Pavitt no es fácil, y sería necesario para una adscripción más correcta utilizar una desagregación de la CNAE a 4 dígitos y d) cuando se refleja en un mapa la localización de algunos de los sectores económicos de base científica y de proveedores especializados, la información suele ocultar la presencia simultánea de grandes y pequeñas firmas con capacidad tecnológica diferente, así como establecimientos donde puede realizarse tareas de valor y contenido innovador muy desigual, asociados a puestos de trabajo con niveles de cualificación contrastados (Méndez, R., 1997 b).

8 Para este trabajo se ha empleado la clasificación de la OCDE de 1997. Al igual que la anterior también encuentra grandes dificultades de aplicación por los continuos cambios que sufren los listados en función del ciclo de vida de las tecnologías. Y en particular para el caso de regiones periféricas, en concreto para Andalucía, por las grandes diferencias existentes en cuanto a nivel tecnológico con los países en donde la OCDE realizó sus cálculos. 
nales que se caracterizan por la realización de desarrollos propios pero estrechamente ligados a las especificaciones y al proceso innovador de clientes y proveedores, favoreciendo para el caso andaluz el impulso de actividades de I+D muy vinculadas a las actividades de Diseño y contratación de servicios de I+D (Ruiz, 2003).

En primer lugar como se muestra en el mapa 3 y 4 las empresas que llevan a cabo actividades de I+D pertenecientes a estos sectores de media y alta tecnología están sobretodo presente en las comarcas que trazan las capitales provinciales o grandes aglomeraciones urbano-industriales y de su entorno: Sevilla, Los Alcores, la Vega y Bajo Guadalquivir; Huelva, El Andevalo Oriental, Condado Doñana; Málaga; Córdoba, Campiña Sur y Subbético; Jaén y Sierra Sur-Martos; Granada; y Almería y el Poniente y Levante almeriense. La capacidad de los ámbitos territoriales andaluces para llevar a cabo actividades de I+D empresarial y en definitiva de innovación no sólo está en estrecha relación con la existencia de un mínimo tejido innovador sino también, aunque en menor medida, con un determinado grado de diversificación productiva y tecnológica. En concreto la correlación de Pearson entre el número total de empresas de $\mathrm{I}+\mathrm{D}$ y el número de sectores con empresas innovadoras es del 0,8 para un nivel de significación del 0,01.

Así podemos apreciar como las áreas en donde se concentran las actividades de I+D tienen (véase mapas 1, 2, 3, 4, 5 y 6):

1. Una mayor presencia de empresas innovadoras de distintas ramas que permiten la existencia de flujos de información y de conocimiento en redes formales e informales de carácter horizontal (entre los distintos sectores o intrasectorial) y vertical (proveedores-clientes). Por ejemplo el área metropolitana de Sevilla cuenta con empresas innovadoras pertenecientes a 16 ramas $\mathrm{CNAE}^{9}$, Málaga en 10, Granada y Córdoba en 9, Bahía de Cádiz en 7, Poniente Almeriense en 5 y Sierra SurMartos en 4.

2. Con la excepción del Poniente Almeriense y la Bahía de Cádiz en donde predomina las empresas dominadas por los proveedores y de producción a gran escala, la realización de actividades de $\mathrm{I}+\mathrm{D}$ se asocia claramente a la presencia de firmas pertenecientes según la terminología de Pavitt y Soete-Miozo a manufacturas y servicios de base científica (Huelva, Granada, Málaga y Sevilla).

3. Igualmente y en relación con lo anterior estas áreas cuentan con empresas con un alto grado tecnológico, de media-alta y alta tecnología, industriales y de servicios.

De esta forma el territorio andaluz se puede clasificar en función de la capacidad de generar actividades de $\mathrm{I}+\mathrm{D}$ en:

1. Comarcas muy dinámicas. Se trata de las comarcas más innovadoras y corresponden a las áreas metropolitanas de Sevilla y Málaga, y las aglomeraciones urbanas de la Bahía de Cádiz, Granada, Córdoba, Huelva y Almería junto con el Poniente Almeriense en las que están presente las medias-altas y altas tecnologías. La significativa presencia de Servicios Avanzados se convierte en el elemento clave de la difusión y generación no sólo de actividades de I+D sino también de innovación.

9 CNAE: Clasificación Nacional de Actividades Económicas. En este trabajo las empresas se han clasificado a través de la CNAE-93 a un dígito para todos los sectores de la economía a excepción de la industria manufacturera que se ha hecho a dos. 
2. Comarcas con gran potencial para realizar actividades de $I+D$. Aquellas en donde la monoespecialización de la estructura productiva innovadora principalmente en sectores de grado tecnológico medio y la falta de una masa crítica de empresas innovadoras limitan el desarrollo de la innovación. Pero son ámbitos que tienen un gran potencial innovador por la presencia de sectores productivos muy dinámicos de carácter primario: agricultura intensiva hortofrutícola y floricultura en la Costa Oeste de Huelva, Campiña de Jerez, Antequera y Levante almeriense; y extracción y trabajo de minerales no metálicos en la comarca de Almanzora; o por la presencia de filiales de grandes multinacionales de media-alta y alta tecnología que descentralizan parte de sus procesos productivos y de innovación en Sierra Sur de Sevilla, Subbético, Jaén y Linares.

3. Y comarcas poco innovadoras en las que la realización de actividades de I+D es muy reducida en correlación con una estructura innovadora poco diferenciada y especializada principalmente en tecnología media y baja: Ándevalo Oriental, Condado-Doñana, Cuenca Minera en Huelva; Corredor de la Plata, Aljarafe-Marismas, Vega, Los Alcores, Morón y Bajo Guadalquivir en la provincia de Sevilla; Campo de Gibraltar y Serranía de Ronda en Cádiz; Los Pedroches, Medio Guadalquivir y Campiña Sur, Condado de Jaén y Úbeda en Jaén; y el Poniente granadino y Costa Tropical en la provincia de Granada.

4. Comarcas no innovadoras en las cuáles no se desarrollan actividades de I+D en relación sobre todo con una insuficiente o inexistencia de una masa de empresas innovadoras: la mayor parte de las comarcas serranas de Huelva, Sevilla, Córdoba, Jaén, Cádiz, Málaga, las más orientales de la provincia de Granada y Almería, y algunas comarcas de la campiña del Guadalquivir muy especializadas productivamente en la agricultura cerealística (Campiña Sur y Campiña Este) o en el sector turístico (Costa del Sol).

\section{La componente territorial y sectorial en la dispersión de las actividades de $\mathrm{I}+\mathrm{D}$ por el territorio andaluz}

Con la intención de valorar de una forma más precisa el factor territorial y sectorial en la proliferación de actividades de I+D empresariales se ha aplicado parcialmente la técnica del shift-share ${ }^{10}$ calculando:

a) El número de empresas de $\mathrm{I}+\mathrm{D}$, o empresas de $\mathrm{I}+\mathrm{D}$ esperadas que habría en cada comarca en el caso de que sus diferentes sectores se comportasen con el mismo nivel de innovación que muestran a escala regional.

b) El número de empresas de Media-alta y Alta Tecnología y que realicen desarrollos propios (Base científica y de Proveedores especializados) que habría en cada ámbito territorial si los diferentes sectores se comportasen igual que la estructura de I+D regional.

10 A semejanza de la realizada por Salom, J. et al., en la publicación Sistema Urbano e Innovación Industrial en el País Valenciano. El Análisis shift-share (reparto proporcional) es una aplicación técnica de tipo predictivo en la cual se comparan los resultados reales con los esperados. Para mayor información sobre la aplicabilidad y deficiencias de la técnica véase Rodríguez Saíz et al. (1986): Política Económica Regional, páginas 102-108. Editorial Alianza. Madrid. 
De esta forma se obtienen dos informaciones que nos ayudan a acercarnos a los factores que inciden en la dinámica innovadora de las unidades territoriales de Andalucía:

1. La diferencia entre el $\%$ de empresas de I+D de Media-alta y Alta Tecnología y de Base científica y de Proveedores especializados reales y el \% esperado de cada una de ellas respectivamente ofrece una estimación del efecto territorial diferencial positivo o negativo que otorga cada ámbito territorial. Es decir la existencia de economías externas y apoyos institucionales que incentiven tanto redes de relaciones interempresariales (subcontratación, oferta y demanda de servicios especializados, intrasectoriales) con el entorno local como el impacto de actuaciones de determinadas instituciones políticas y sociales capaces de generar medios innovadores.

2. Por otra parte, la diferencia entre el \% de empresas esperadas de I+D de Mediaalta y Alta Tecnología y de Base Científica y de Proveedores especializados y el $\%$ existente realmente de cada una de ellas en el conjunto regional nos permite apreciar el efecto sectorial que está afectando a cada comarca. O dicho de otra forma qué papel juega las diferentes especializaciones sectoriales de cada espacio a sabiendas de que cada rama productiva tiene una determinada capacidad de innovación y crecimiento en función de la dinámica y la estructura de sus mercados.

Como se aprecia en los mapas 7 y 8 en la mayor parte del territorio andaluz no se dan ni condiciones sectoriales ni territoriales para el desarrollo de actividades de I+D. Y cuando se dan están íntimamente relacionadas. La mayoría de los ámbitos territoriales no cuentan ni con un número suficiente de empresas innovadoras que permitan las relaciones intra e intersectoriales de conocimiento ni con otros impulsos de carácter territorial que incentiven la innovación. Incluso comarcas muy innovadoras (Córdoba, Granada, Málaga, Almería y Cádiz) realizan menos I+D de lo que le pertenecería por el volumen de empresas innovadoras que posee ante la falta de requisitos territoriales y sectoriales que impulsen dichas actividades.

Por el contrario el impulso territorial y sectorial es positivo para comarcas con pocas empresas de I+D como La Cuenca Minera, Corredor de la Plata, Poniente Granadino, Los Pedroches y Condado de Jaén. El elevado esfuerzo comarcal en actividades de I+D de estas comarcas ya sea por la actuación de la administración, otros agentes sociales y económicos y/o por la estructura productiva es de especial significación para la construcción de ejes territoriales de innovación (I+D) que dispersen las actividades de I+D desde las grandes urbes hacia las áreas más periféricas.

Pero la principal deficiencia de estas regiones, y a su vez causa de la inexistencia de un subsistema empresarial de I+D, es la falta de factores territoriales y sectoriales que propulsen las actividades de I+D de Media-alta y Alta tecnología. Como se estima en los mapas 9 y 10 en Andalucía únicamente se dan las condiciones necesarias para la difusión de estas actividades en estos sectores en las capitales provinciales y en otras importantes aglomeraciones urbano-industriales de la región. A las que hay que añadir, más por el efecto de la estructura sectorial que por condiciones territoriales las comarcas del Andevalo Oriental, La Vega, y Campiña Sur. Por lo tanto si selectiva espacialmente era la propagación de actividades de I+D más aún son las de Media-alta y Alta tecnología que se concentran en grandes áreas urbanas como Jaén, Granada, Almería, Bahía de Cádiz y Málaga, espacios que por otra parte poseen bajos esfuerzos en la generación de I+D aunque él que se realiza es de alto valor añadido. 
Igualmente, y en relación con lo anterior, sigue siendo negativo para la mayor parte del territorio las condiciones que inciden en la generación de actividades de I+D empresariales de base científica y de proveedores especializados, y por tanto en la realización de desarrollos propios (mapas 11 y 12). Aunque en este caso se aprecia como en las áreas más innovadoras (I+D) actúan más las características territoriales que poseen dichos espacios que la estructura sectorial. Mientras que para el resto de comarcas que realizan I+D, con mucho menor número de empresas, incide claramente más la existencia de una estructura sectorial de innovación de manufacturas de proveedores especializados y en menor medida de base científica.

\section{Conclusiones}

La dimensión y las características de la difusión espacial de las actividades de I+D en regiones periféricas como la andaluza viene condicionada claramente por la disposición territorial y estructura sectorial del tejido productivo más innovador. La distribución espacial de las firmas innovadoras muestra en el territorio andaluz grandes desequilibrios que se traducen en desigualdades para generar innovación, y sobre todo actividades de I+D. Estas disparidades no sólo están unidas al número y proximidad espacial de agentes públicos y privados que ofrecen las economías de aglomeración, sino también a cuestiones de tipo sectorial.

La dispersión territorial de la I+D se encuentra con varios obstáculos de tipo cuantitativo y cualitativo:

a) Por una parte una escasa masa crítica de empresas innovadoras. En lo referente a las unidades del subsistema empresarial de I+D sólo suponen el 0,07\% de las empresas andaluzas y el 16,40\% de las innovadoras; y están localizadas en el área metropolitana de Sevilla y capitales provinciales o grandes centros industriales (Ruiz, 2003).

b) Y por otra una elevada concentración territorial de los sectores con mayor propensión a innovar y realizar actividades de I+D. Los sectores de alta tecnología están presentes sobre todo en las áreas metropolitanas. Mientras que en el resto del territorio los de media y baja tecnología, sectores tradicionales de producción a gran escala o dominados por proveedores, dibujándose por tanto un mapa de innovación regional, especialmente de I+D muy discontinuo y con bajo nivel tecnológico.

La elevada concentración espacial de los elementos básicos de las redes formales o informales de conocimiento (empresas industriales y de servicios, centros públicos de investigación, organismos e instituciones,...) dificulta la dispersión territorial de las actividades de I+D e innovación. Para que se produzca la dispersión de las actividades de I+D desde la grandes urbes hacia las áreas más periféricas es necesario la consolidación de ejes territoriales de innovación a través de la generación de impulsos territoriales y sectoriales. En concreto para el caso andaluz se pueden apreciar algunos signos de cambio importantes con el nacimiento de ciertos corredores territoriales de innovación por las áreas montañosas del interior, sobre todo por el Subbético.

En definitiva, con el objetivo de aumentar la competitividad regional y de reducir no sólo la disparidad existente con las regiones europeas sino también de que no se agranden los desequilibrios territoriales internos en la región, es necesario cambiar la capacidad de innovación de las empresas regionales y de generar un nivel mínimo de capacidades de 
I+D. El afloramiento de actividades de I+D en regiones atrasadas pasa por incrementar la capacidad de innovación aspecto que, a su vez, depende del establecimiento de un sistema regional innovador eficiente, un medio innovador ${ }^{11}$ a escala regional. Lo cual constituye una condición previa para el incremento de la inversión pública y privada en el campo de la innovación.

Las características estructurales, tecnológicas y espaciales del tejido empresarial de este tipo de regiones, y en particular del innovador obliga necesariamente a tomar una estrategia innovadora que apoye tanto la generación de I+D en sectores de alta, media como en los de baja tecnología y en la PYME regional. Con ello se podría estimular tanto la demanda como la oferta de innovación que permita la necesaria sinergia entre la tecnología (I+D, otras actividades innovadoras) con el sistema científico desde un punto de vista productivo y territorial. El aumento del nivel tecnológico del tejido empresarial regional, y del territorio en particular, y apoyándose en la proximidad espacial, creará un aumento de la demanda que estimulará las relaciones tanto inter e intraempresariales como con el resto de agentes del sistema de innovación regional.

En regiones atrasadas, y siguiendo a Veltz (1999), existen factores económicos y territoriales que presionan hacia la remetropolitanización de las actividades económicas y de la innovación, frenando así la tendencia a la descentralización. Poniendo como ejemplo el caso de Andalucía se da una configuración económico-territorial «metrópolis-red» conformada por las metrópolis y los principales centros regionales en tanto:

a) La gran empresa integradora de redes formales o informales de empresas especializadas, ligadas por relaciones de subcontratación o de colaboración, necesita algún tipo de aglomeración. Espacios en los que se concentran las empresas de la misma y las diferentes actividades económicas que permite dividir el trabajo y compartir la profesionalidad local (Benko y Lipietz, 1992).

b) La empresa en un contexto en el que la innovación se acelera y se convierte en una condición de supervivencia, necesita ramificar y a la vez diversificar sus «tentáculos» hacia arriba (relaciones con la investigación y el desarrollo, servicios especializados para la producción) y hacia abajo (relaciones con los mercados, servicios de intermediación (Veltz, 1999).

En consecuencia en este tipo de regiones se producen procesos de remetropolización en base a la elevada concentración de las actividades innovadoras, especialmente las de I+D y del terciario avanzado en las capitales provinciales; aumentándose el riesgo de que se cree un territorio que mantenga permanentemente dos velocidades. Y aunque se pueda percibir cierta dispersión espacial de las actividades de I+D hacia ámbitos más rurales la producción innovadora de éstos espacios no se puede comparar con la de las grandes áreas urbanas regionales.

\section{Bibliografía}

AYDALOT, PH. (1986 a): «Les technologies nouvelles et les formes actuellles de la Division Spatiale du Travail». Dossier du Centre Economie-Espace-Environnoment $n^{\underline{a}} 47$. Université de Paris I.

AYDALOT, PH. (1986 b): Milieux innovateurs en Europe. GREMI. París.

11 Hablar de medio innovador supone tratar con redes de flujos y vínculos estrechos entre las empresas y con el territorio en que se asientan (Méndez, 1997 a). 
BENKO, G. y LIPIETZ, A., eds. (1992): Les régions qui gagnent. Districts et réseaux: les nouveaux paradigmes de la géographie économique, P.U.F., París. (Traducción al español en las regiones que ganan. Distritos y redes. Los nuevos paradigmas de la geografía económica, Ediciones Alfons el Magnànim-I.V.E.I., Valencia, 1994).

BRESCI Y MALERBA, F. (1997): «Sectorial Innovation Systems: Technological Regimes, Schumpeterian Dynamics, and Spatial Boundaries». En Edquist, C. (ed.) Systems of Innovation. Technologies, Institutions and Organizations (pp. 130-155). London and Washington, Pinter.

CARLSSON, B. (ed.) (1995): Technological systems and economic performance: the case of factory automation. Dordrecht, Kluver.

COMISIÓN EUROPEA (2004): Tercer informe intermedio sobre la cohesión económica y social. http://inforegio.es

DEMATTEIS, G. (1995): Progetto implicito. Franco Angelo. Milán.

EDQUIST, C. (ed.) (1997): Systems of Innovation. Technologies, Institutions and Organizations. London and Washington. Pinter. Publishers.

HEIJS, J. (2001): Sistemas Nacionales y Regionales de Innovación política tecnológica: una aproximación teórica. Documento de Trabajo no 24. Octubre de 2001. IAIF (Instituto de Análisis Industrial y Financiero de la Universidad Complutense de Madrid).

JORDÁ BORRELL, R. (2004): «Servicios a empresas (SEMP) y Territorio. Actas de la II Reunión del Grupo de Trabajo Geografía de los Servicios de la AGE. Sevilla, pp. 215-243.

KOSCHATZKY, K. (1997): «Innovative Regional Development Concepts and technology based firms». En Koschatzky (ed.): Technology based firms in the innovation process: Management, financing and regional networks.

KOSCHATZKY, K. (2000): «The regionalisation oof innovation polucy in Germany-theoretical Foundations and recent experience». Arbeitspapiere Unternehmen und Región $\mathrm{n}^{\mathrm{o}} 1$.

LUCAS, R. (1988): On the Mechanics of Development Planning. Journal of Monetary Economics, 22.

LUNDVALL, B. A. (ed.) (1992): National Systems of Innovation: towards a Theory of Innovation and Interactive Learning. London. Pinter.

MARSHALL, (1919): Industry and Trade. London. McMillan.

MENDEZ, R. (1997 a): «Procesos de innovación tecnológica y reorganización del espacio industrial». VI Jornadas de Geografía Industrial. Nuevas Tecnologías, trabajo y localización industrial. Asociación de Geógrafos Españoles (AGE). Grupo de Geografía Industrial. Pp. 158-190.

MÉNDEZ, R. (1997 b): Geografía Económica. La lógica espacial del capitalismo global. Ed. Ariel. Barcelona.

OCDE (1994): Proposed Standard Practice for Surveys of Research and Experimental Development. Frascati-Manual. París.

OCDE (1992): Proposed Guidelines for Collecting and Interpreting Technological Innovation. Data. Oslo-Manual. París.

OCDE (1997): Révision des classifications des secteurs et des produits de haute technologie. Doc. OCDE/GD (97) 216.

PAVITT, K. (1984): «Sectoral Patterns of Technological Change: Towards a Taxonomy and Theory», Research Policy 13, pp. 343-373.

PAVITT, K.; ROBSON, M. y TOWNSED, J. (1989): «Technological Accumulation, Diversification and Organisation in UK Companies, 1945-1983», Management Sciencie, 35.1, pp. 81-99.

PERROUX, (1955): «Note sur la notion de pôle de croissance» Économie Appliquée, 7.

PORTER, (1990): The Comparaative Advantage of Nations. Free Press and Macmillan.

ROMER, P. (1986): «Increasing Returns and Long-Run Growth». Journal of Political Economy, 94.

ROMER, P. (1990): «Endegenous Technological Cange». Journal of Political Economy, 98.

RUIZ, F., (2003): Las actividades de I+D en el subsistema empresarial de Innovación Andaluz. El Espacio relacional de las empresas de $I+D$. Tesis doctoral (inédita).

SALOM, J.; ALBERTOS, J. M., PITARCH, D., DELIOS, E. (1999): Sistema Urbano e Innovación Industrial en el País Valenciano. Universitat de València. Valencia.

STERN, S.; PORTER, M. E. y FURMAN, J. L. (2000): The Determinants of National Innovative Capacity. Working paper 7876. National Bureau of Economic Research, INC. 
SOETE, L. y MIOZZO, M. (1989): «Trade and Development in Services. A technological Perspective», Working Paper no. 89-031, MERIT, Maastricht.

TEECE, D. (1987): Profiting from technological innovation research. Pp. 285-305.

VÁZQUEZ BARQUERO, (1997): «Desarrollo endógeno: mecanismos institucionales y culturales». XXIII Reunión de Estudios Regionales: Globalización, Unión Europea, políticas regionales. Ed. Revista Valenciana d'Estudis Autonómics. № 21 (Extraordinario). Valencia. Pp. 71-91.

VELTZ, P. (1999): Mundialización, ciudades y territorios, Barcelona. Ed. Ariel. 
ANEXO 1. BASE COMARCAL

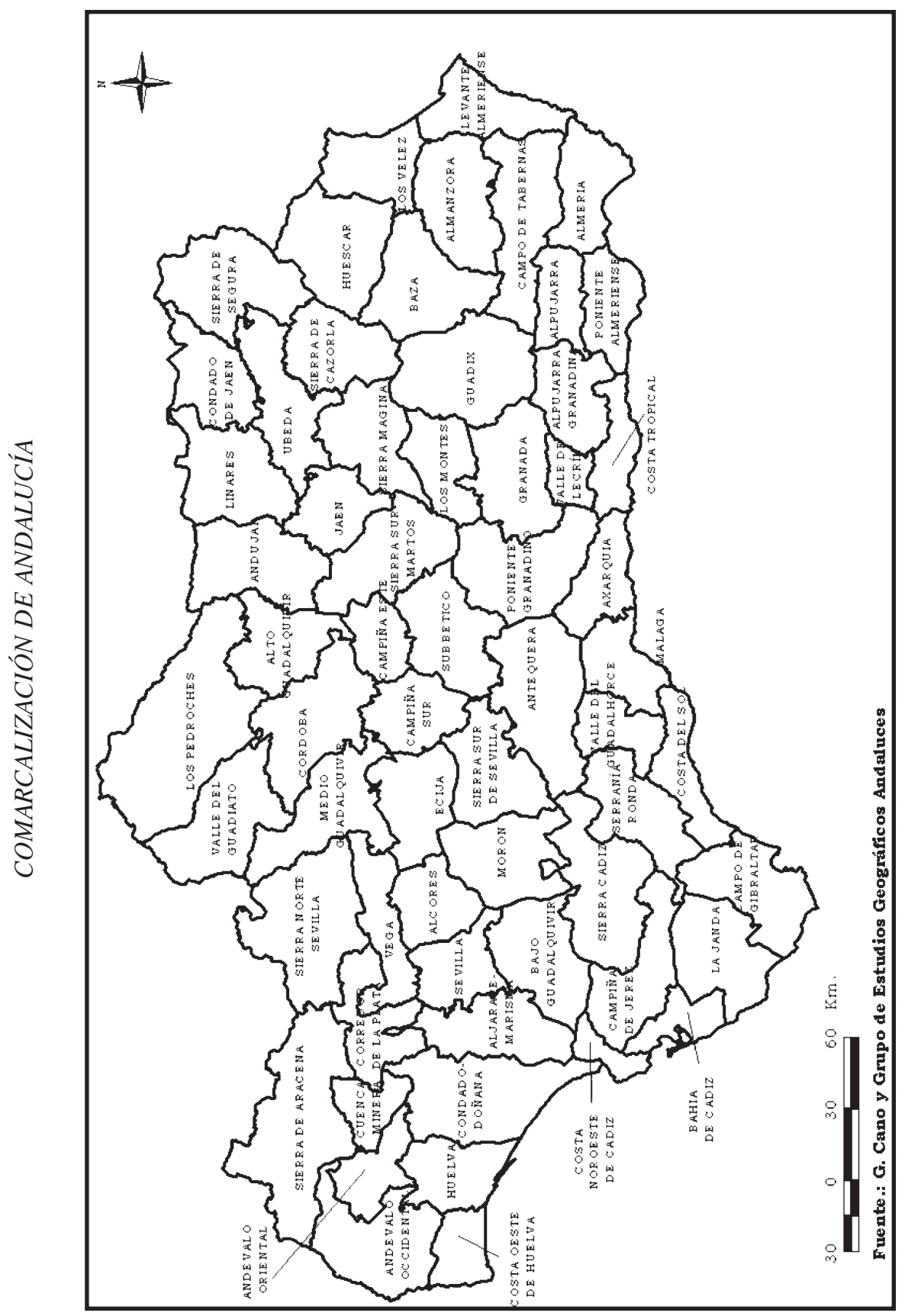




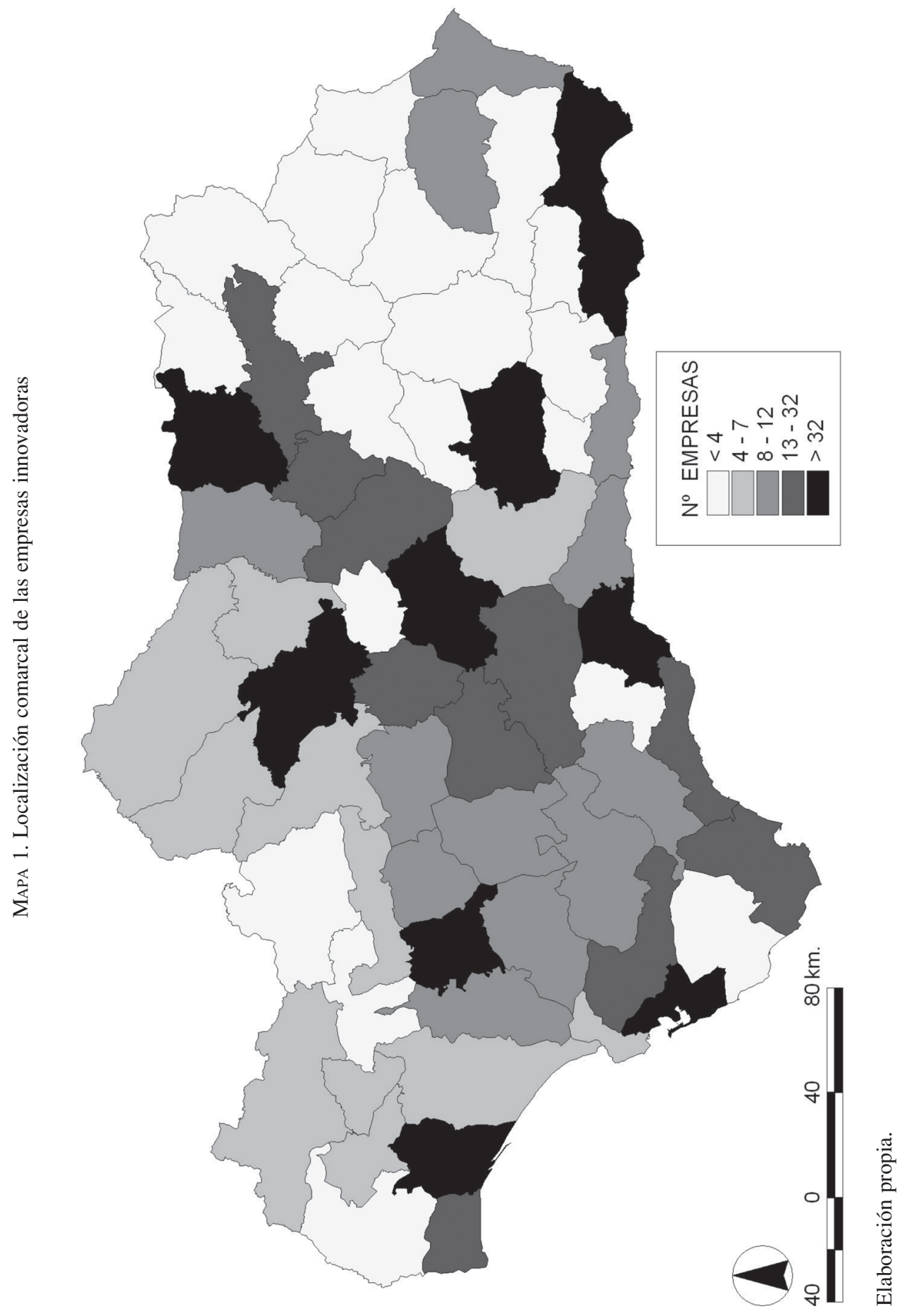




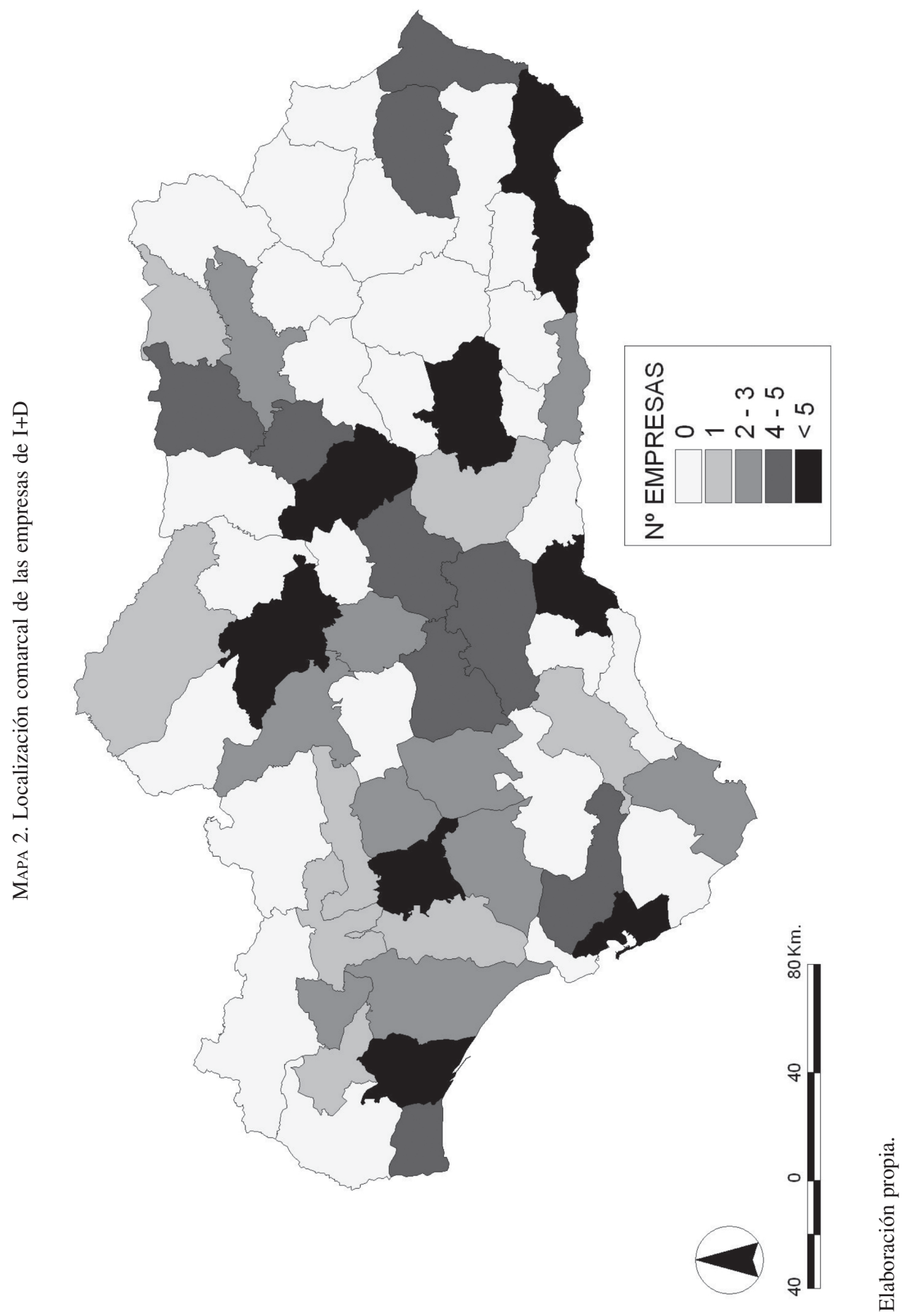




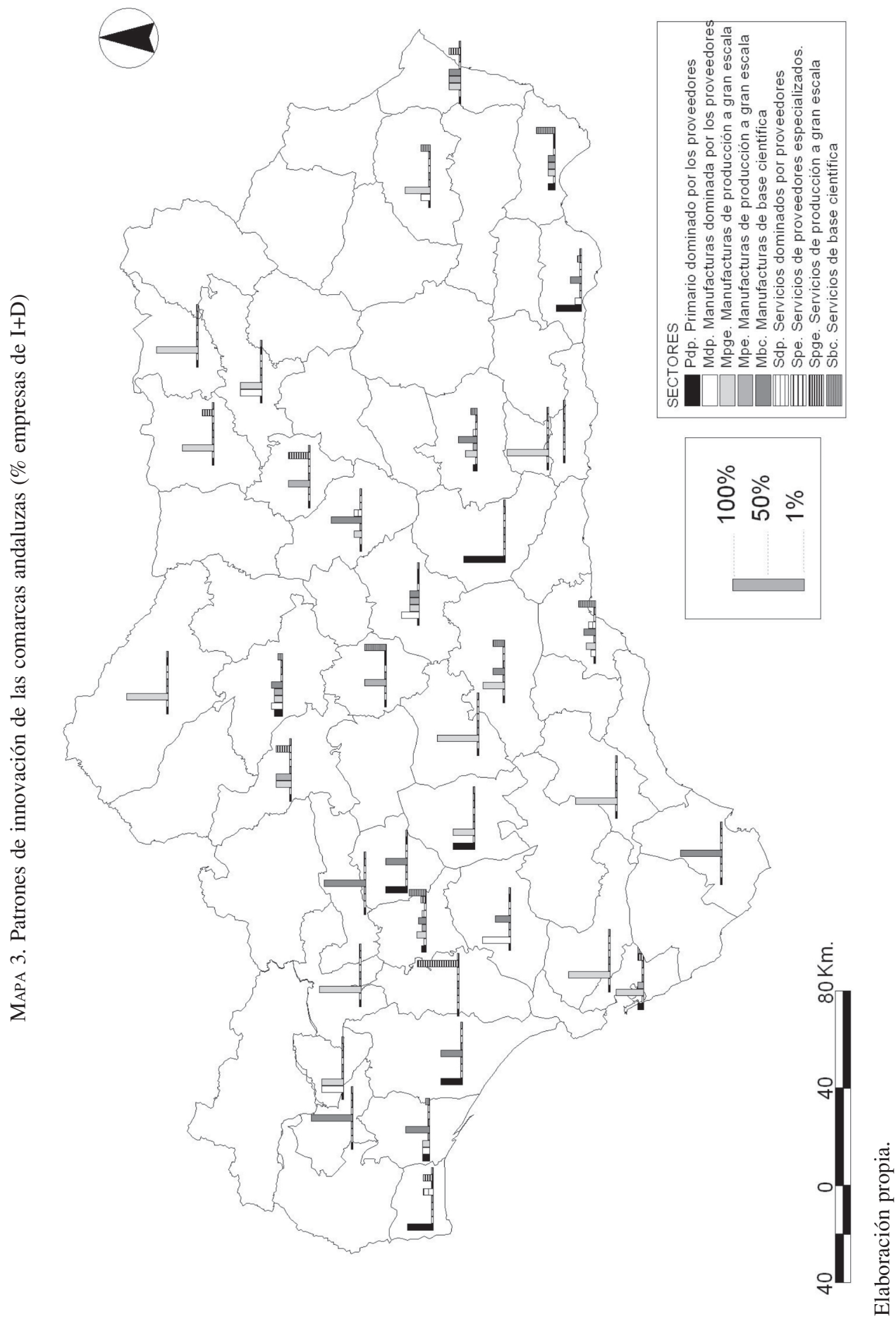




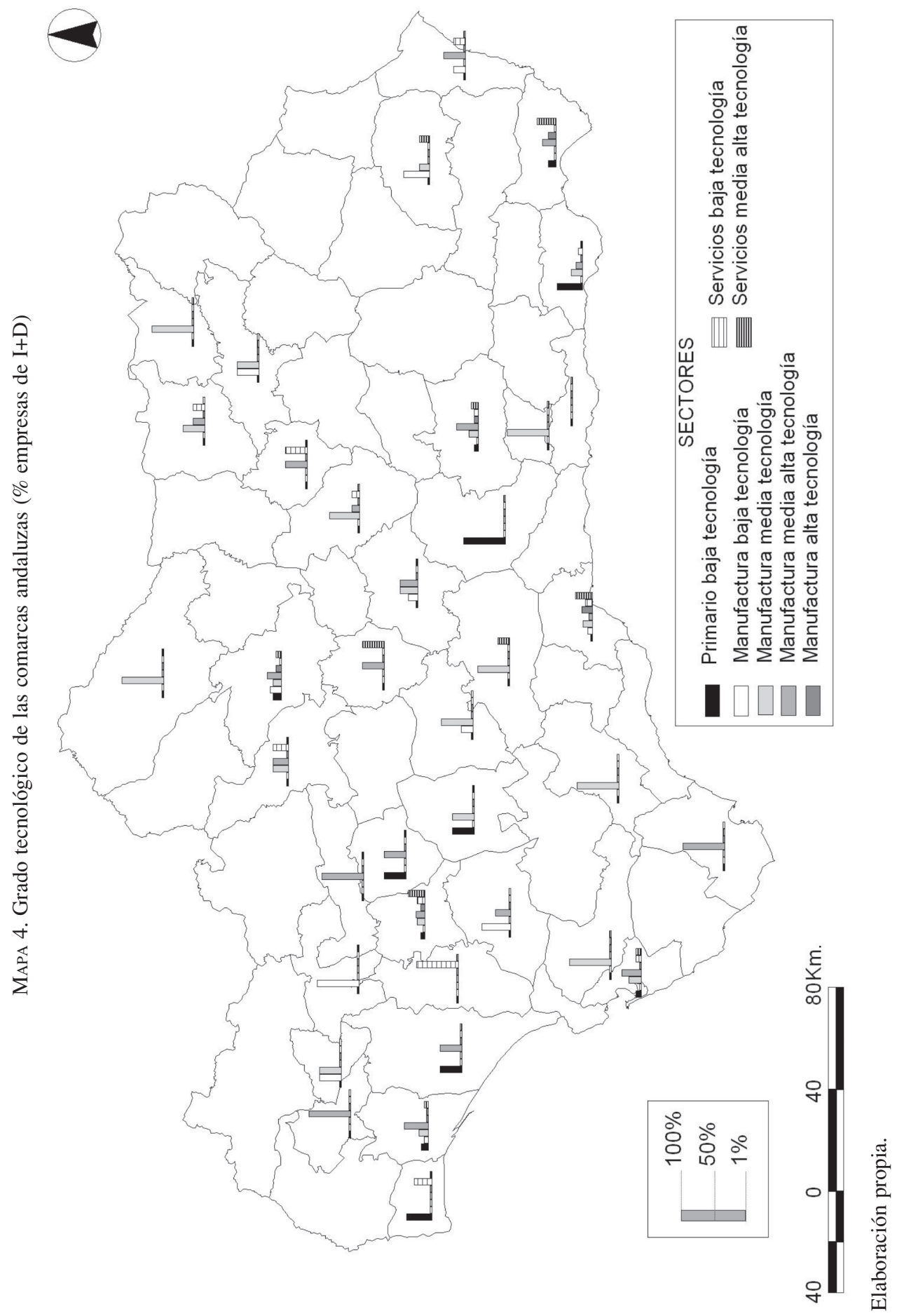




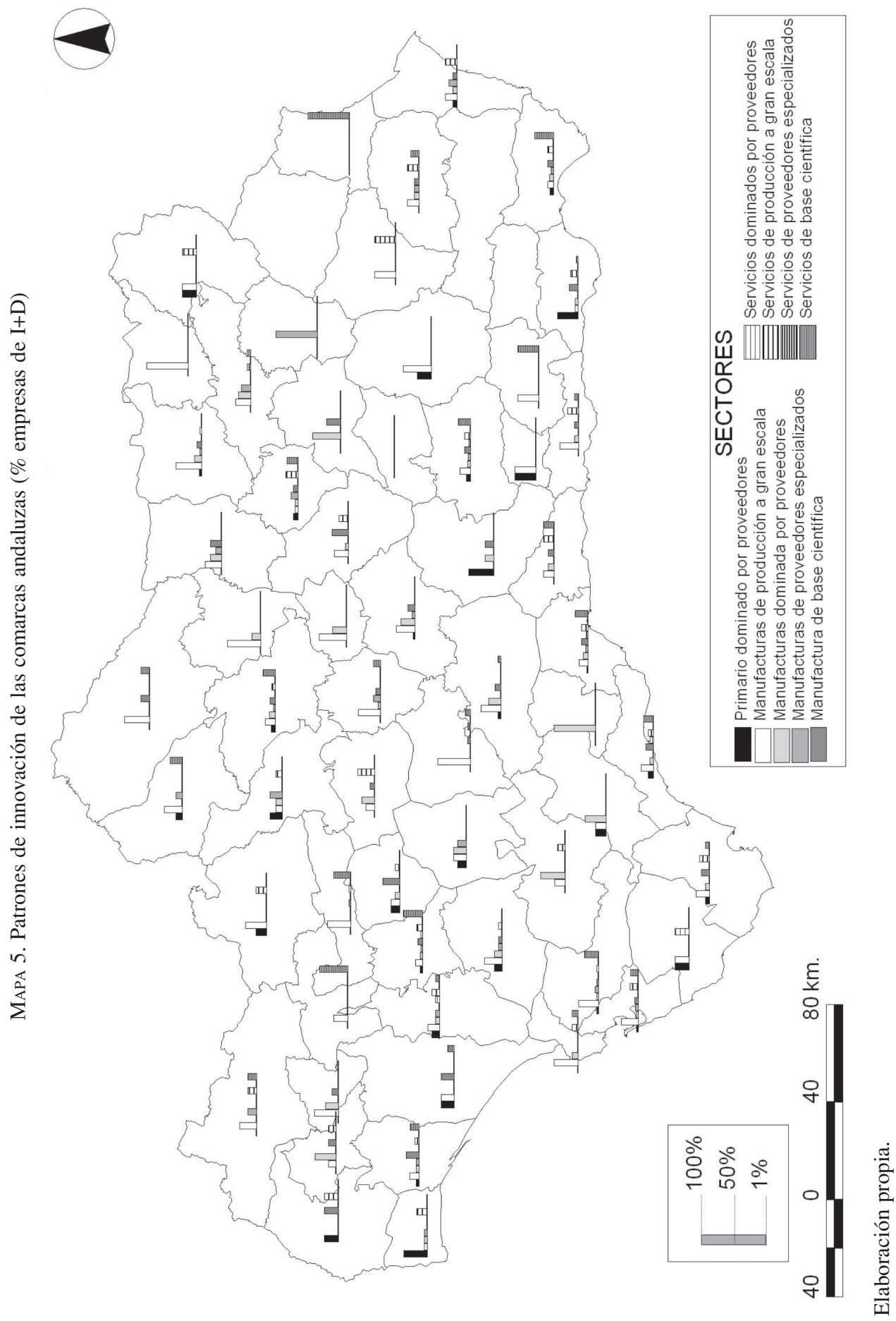




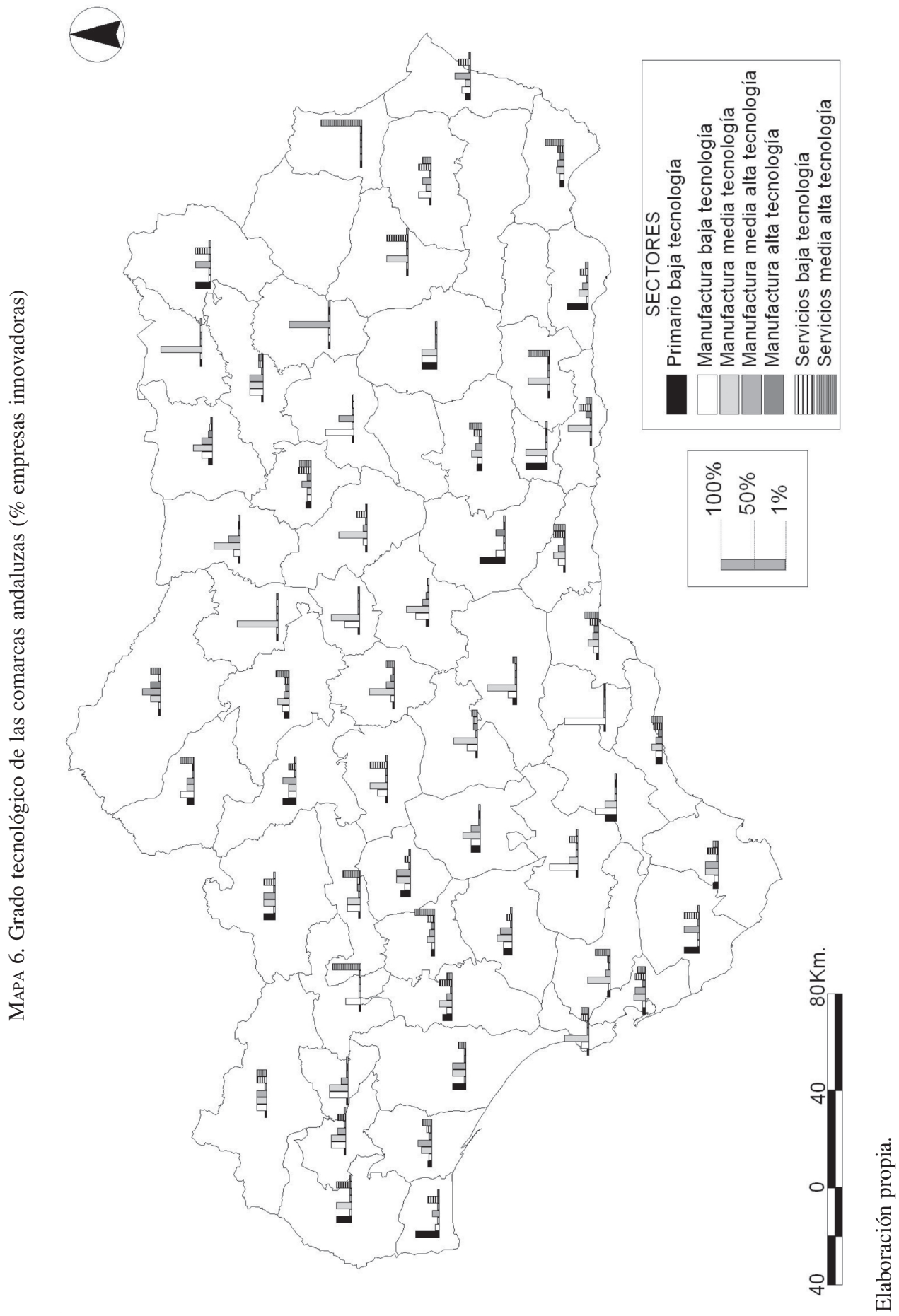


MAPAS 7 y 8 . Factor territorial y sectorial en la generación de empresas de I+D
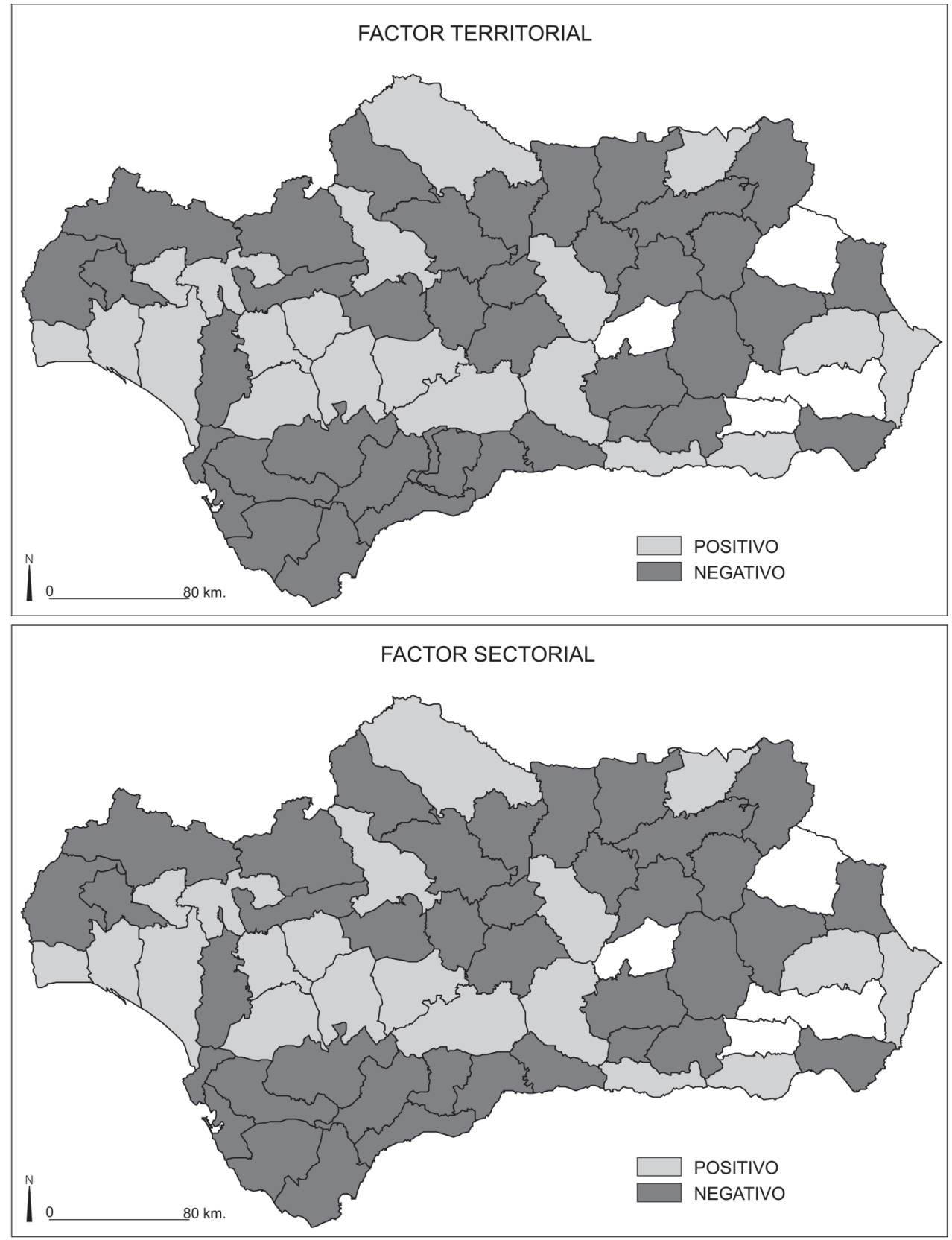

Elaboración propia. 
MAPAS 9 y 10. Factor territorial y sectorial en la generación de empresas de media-alta y alta tecnología
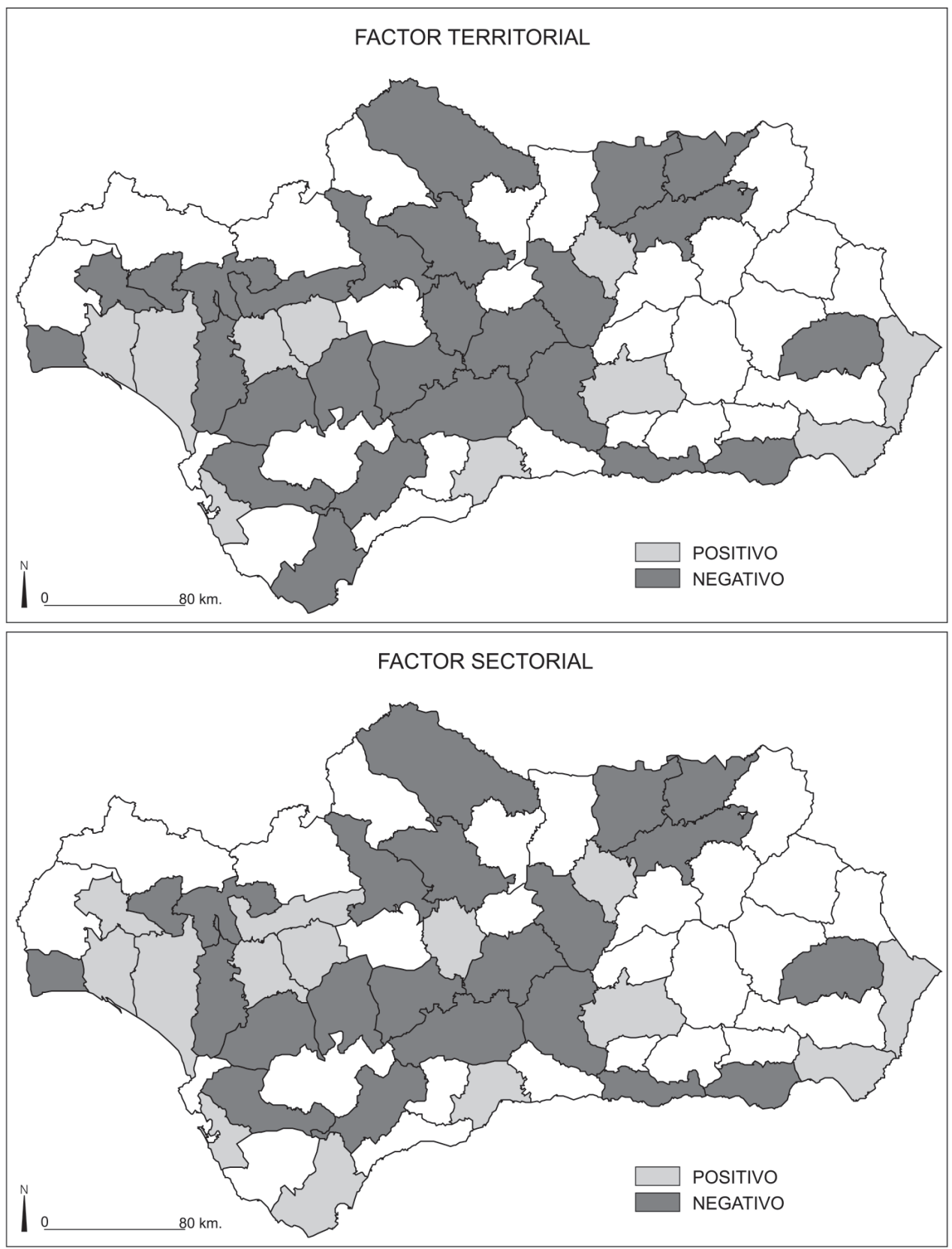

Elaboración propia. 
MAPAS 11 y 12. Factor territorial y sectorial en la generación de empresas de base científica y proveedores especializados
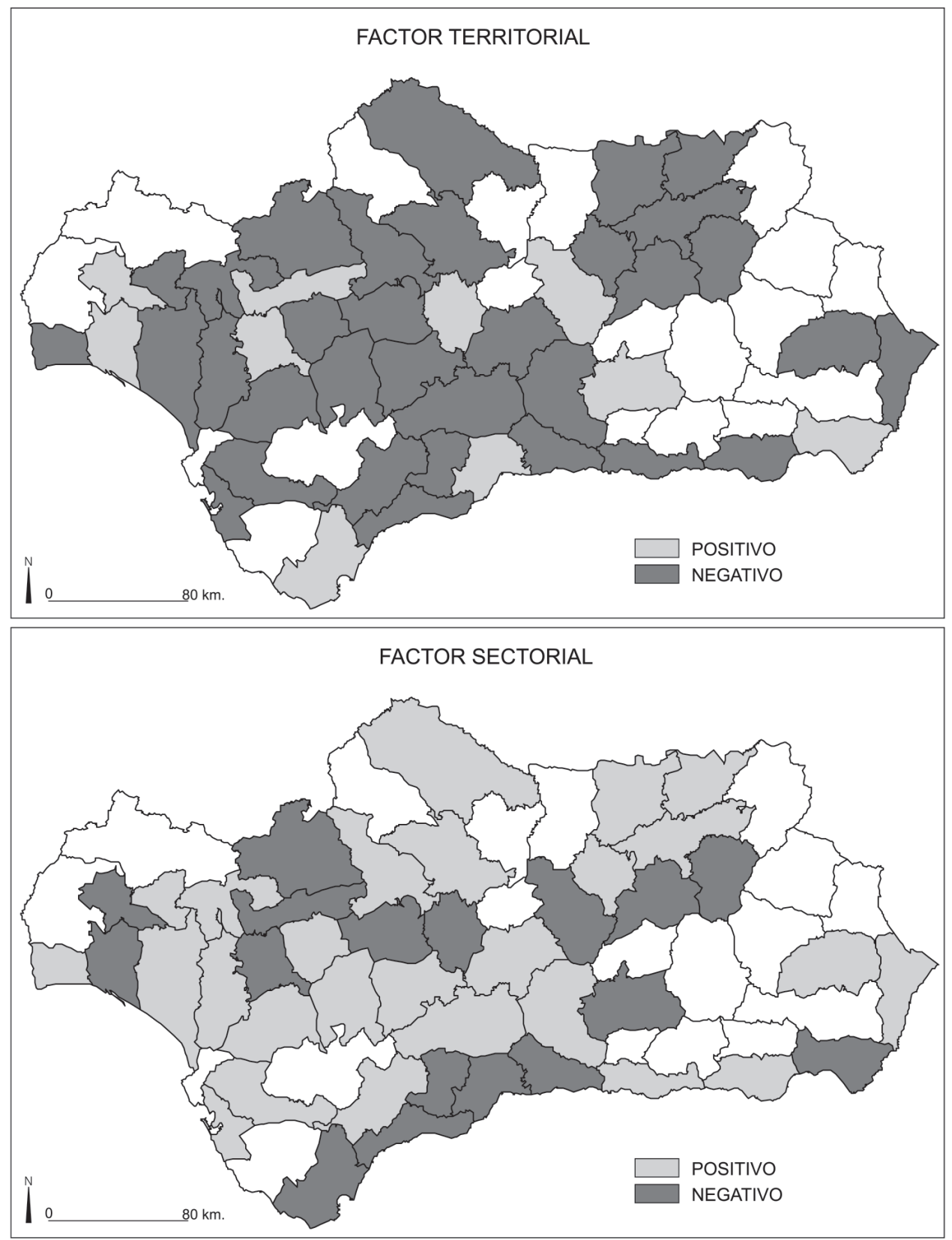

Elaboración propia. 